\title{
DEVELOPMENT OF A NEW SINGLE CRYSTAL SUPERALLOY FOR INDUSTRIAL GAS TURBINES
}

\author{
T.Hino, T.Kobayashi, Y.Koizumi, H.Harada and T.Yamagata \\ High Temperature Materials 21 Project, National Research Institute for Metals \\ 1-2-1 Sengen, Tsukuba Science City, Ibaraki 305-0047, Japan
}

\begin{abstract}
$\underline{\text { Abstract }}$
In order to raise the turbine inlet gas temperature to improve thermal efficiency of gas turbines, turbine blade and vane materials are required to have high creep rupture strengths. In the present study, a new single crystal superalloy with a moderate Re addition $(2.4 \mathrm{wt} \%)$ has been developed. The alloy shows a higher creep rupture strength than the second and even the third generation single crystal superalloys.

The composition of the developed single crystal superalloys were designed with a computer aided alloy design program which was developed in National Research Institute for Metals (NRIM-ADP) and finally one alloy was selected experimentally. The developed single crystal superalloy had a stress rupture temperature advantage over $30^{\circ} \mathrm{C}$ in comparison with the second gencration single crystal superalloys at the $137 \mathrm{MPa} / 10^{5}$ hours condition. The developed alloy has a large negative lattice misfit. The large negative lattice misfit enhances the formation of continuous $\gamma^{\prime}$ platelets, the so-called raft structure, and a fine interfacial dislocation network during creep tests. These are considered to prevent the movement of dislocations and thus decrease the creep strain rate.
\end{abstract}

\section{Introduction}

Many combined cycle power plants have been in operation due to high thermal efficiency and good operatabilty in contrast with steam turbine power plants ${ }^{[1]}$. The combined cycle power plant is mainly composed of gas turbines, steam turbines, and heat recovery steam generators. The thermal efficiency of the combined cycle power plant can be improved by raising the inlet gas temperature of gas turbines. To increase the inlet gas temperature, the materials for turbine blades and vanes are required to have higher creep rupture strength.

Ni-base single crystal (SC) superalloys have higher creep strength in comparison with conventionally cast and directionally solidified superalloys and are now used in the new generation of gas turbine plant ${ }^{[2][3]}$. Creep rupture strength of SC superalloys are reported to be improved by adding $\mathrm{Re}$; second generation $\mathrm{SC}$ superalloys contain about $3 \% \mathrm{Re}^{[4][5][6]}$ and third generation $\mathrm{SC}$ superalloys contain 5 to $6 \% \operatorname{Re}{ }^{[6][7][8]}$. However, it is also reported that adding $\operatorname{Re}$ to SC superalloys tends to cause Re-rich Topologically Closed Packed (TCP) phase precipitation ${ }^{[9][10]}$ which is known to reduce creep rupture strength. 
In the present study, it was intended to develop a new SC superalloy which has excellent phase stability and creep strength in comparison with second and even third generation $\mathrm{SC}$ superalloys with a moderate amount of Re addition.

\section{Alloy Development}

Alloy design was conducted with the NRIM-ADP. This program can estimate mechanical properties by equations derived empirically from mechanical properties of SC superalloys, volume fraction of $\gamma^{\prime}$ phase, lattice misfit between $\gamma$ and $\gamma^{\prime}$ phases, and concentrations of solid solution elements in these phases ${ }^{[11]}$. Schematic flow of this program is shown in Figure 1.

The alloy was designed to have superior creep rupture strength by an effective use of negative lattice misfit ( $\left.a \gamma>a \gamma^{\prime}\right)$.

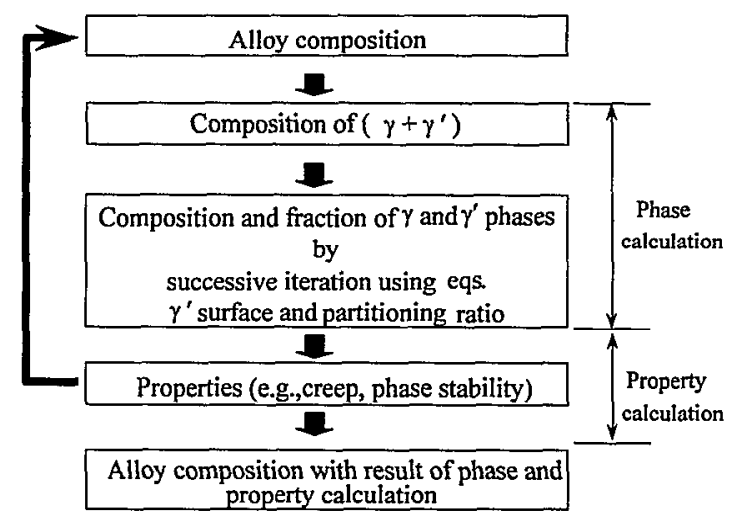

Figure 1: Schematic flow chart of alloy design program.
Other properties such as long-term phase stability, corrosion/oxidation resistance and castabilty were also considered. Creep rupture life at $1100^{\circ} \mathrm{C} / 137 \mathrm{MPa}$ was designed to be longer than $200 \mathrm{~h}$ (e.g., $100 \mathrm{~h}$ for CMSX-4). $\mathrm{Re}$ content was designed to be less than $2.5 \%$ which prevents precipitation of TCP phases and make the alloy cheaper than present second and third generation SC superalloys. The alloy density was set below $8.9 \mathrm{~g} / \mathrm{cm}^{3}$ and the solution heat treatment window was designed to be larger than $50^{\circ} \mathrm{C}$. The phase stability was estimated by a Solution Index (SI) value. SI values is defined as, $\mathrm{SI}=\Sigma(\mathrm{Ci} / \mathrm{CLi})$, where $\mathrm{Ci}$ is an atomic fraction of $i$-th element in $\gamma^{\prime}$ phase and $\mathrm{CLi}$ is a solubility limit of $i$-th element in $\gamma^{\prime}$ phase of the $\mathrm{Ni}$-Al-i-th element ternary system. If the SI value exceeds 1.25 , precipitation of TCP phases is predicted.

Alloy A was designed to have a volume fraction of $\gamma^{\prime}$ phase of about $60 \%$ and maximum content of solid solution elements without exceeding the SI value 1.25. As Re tends to segregate in dendrite core areas and SI value happened to exceed the critical value in some areas, then, alloy $B$ and $C$ were made by diluting alloy A with $\mathrm{Ni}-8 \mathrm{wt} \% \mathrm{Al}$. Chemical compositions of these alloys are shown in Table I.

\section{Experimental Procedure}

Single crystal bars of $10 \mathrm{~mm}$ dia. were cast with the directionally solidified furnace in NRIM. After checking that the longitudinal axes of these single crystal bars were within $15 \mathrm{deg}$ from the [001] orientation, heat treatments were conducted with the sequences shown in Figure 2 and Table II.

Solution heat treatments were considered with temperatures ranging from 1280 to $1360^{\circ} \mathrm{C}$, to dissolve $\gamma^{\prime}$ phase into $\gamma$ phase without incipient melting.

Table I Chemical composition of tested and reference alloys.

\begin{tabular}{lccccccccccc}
\hline & Co & Cr & Mo & W & Al & Ti & Ta & Hf & Re & Ni & $\begin{array}{c}\text { Solution } \\
\text { Index }\end{array}$ \\
\hline Alloy A & 8.0 & 5.0 & 2.0 & 9.0 & 5.2 & 0.5 & 6.2 & 0.1 & 2.5 & Bal. & 1.24 \\
\hline Alloy B (TMS-82+) & 7.8 & 4.9 & 1.9 & 8.7 & 5.3 & 0.5 & 6.0 & 0.1 & 2.4 & Bal. & 1.20 \\
\hline Alloy C & 7.5 & 4.7 & 1.9 & 8.5 & 5.4 & 0.5 & 5.8 & 0.1 & 2.4 & Bal. & 1.16 \\
\hline CMSX-4 & 9.0 & 6.5 & 0.6 & 6.0 & 5.6 & 1.0 & 6.5 & 0.1 & 3.0 & Bal. & 1.12 \\
\hline TMS-75 & 12.0 & 3.0 & 2.0 & 6.0 & 6.0 & - & 6.0 & 0.1 & 5.0 & Bal. & 1.10 \\
\hline
\end{tabular}




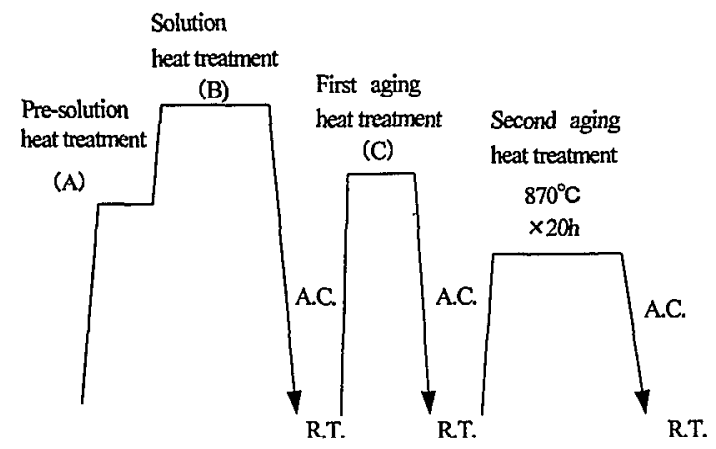

Figure 2 : Heat treatment cycle of tested alloys.

Table II Heat treatment condition of each cycle.

\begin{tabular}{|l|c|c|c|}
\hline & $\begin{array}{c}\text { Pre-solution } \\
\text { heat } \\
\text { treatment } \\
\text { (A) }\end{array}$ & $\begin{array}{c}\text { Solution } \\
\text { heat } \\
\text { treatment } \\
\text { (B) }\end{array}$ & $\begin{array}{c}\text { First aging } \\
\text { heat } \\
\text { treatment } \\
\text { (C) }\end{array}$ \\
\hline Alloy A & - & $1300^{\circ} \mathrm{C} \times 4 \mathrm{~h}$ & $1100^{\circ} \mathrm{C} \times 1 \mathrm{~h}$ \\
\hline Alloy B & $1300^{\circ} \mathrm{C} \times 1 \mathrm{~h}$ & $1320^{\circ} \mathrm{C} \times 5 \mathrm{~h}$ & $1150^{\circ} \mathrm{C} \times 4 \mathrm{~h}$ \\
\hline Alloy C & $1300^{\circ} \mathrm{C} \times 1 \mathrm{~h}$ & $1320^{\circ} \mathrm{C} \times 5 \mathrm{~h}$ & $1150^{\circ} \mathrm{C} \times 4 \mathrm{~h}$ \\
\hline
\end{tabular}

After the heat-treatments, creep test specimens ( $4 \mathrm{~mm}$ dia. with $22 \mathrm{~mm}$ gage section length) were machined from these single crystal bars. Creep tests were performed at $900^{\circ} \mathrm{C} / 392 \mathrm{MPa}$, $1000^{\circ} \mathrm{C} / 196 \mathrm{MPa}$ and $1100^{\circ} \mathrm{C} / 137 \mathrm{MPa}$. In addition to these conditions, alloy B (TMS-82+) was further tested at $1100^{\circ} \mathrm{C} / 158 \mathrm{MPa}, 1100^{\circ} \mathrm{C} / 98 \mathrm{MPa}$ and $1000^{\circ} \mathrm{C} / 245 \mathrm{MPa}$.

To investigate the high temperature creep mechanism, specimens for interrupted creep tests at 64hours under $1100^{\circ} \mathrm{C} / 137 \mathrm{MPa}$ were prepared with alloy B (TMS-82+) and TMS-75. TMS-75 is a third generation SC superalloy also developed in $\operatorname{NRIM}^{[7]}$. Microstructural examination was conducted by transmission electron microscopy (TEM) and scanning electron microscopy (SEM). These specimens were cut to thin slices both normal and parallel to the longitudinal [001] directions. The thin foil specimens for TLM observation were prepared using an electro-polishing method with a reagent consisting of $50 \mathrm{~m} \ell \mathrm{HClO}_{4}$ and $250 \mathrm{~m} \ell \mathrm{C}_{2} \mathrm{H}_{4} \mathrm{O}_{2}$ at $5^{\circ} \mathrm{C}$. Specimens for SEM observation were mounted in molds, polished and etched using an aqua regia reagent consisting of $10 \mathrm{~m} \ell \mathrm{HNO}_{3}$ and $30 \mathrm{~m} \ell \mathrm{HCl}$ diluted by $40 \mathrm{~m} \ell \mathrm{C}_{3} \mathrm{H}_{8} \mathrm{O}_{3}$. High temperature phase stability of these alloys were evaluated with the microstructure in end section of creep specimens after tests.

\author{
The Results and Discussion
}

\section{Selection of Alloy}

Figure 3 shows the creep rupture strengths plotted against SI values. Except for a low temperature and high stress condition such as $900^{\circ} \mathrm{C} / 392 \mathrm{MPa}$, alloy $\mathrm{B}$ is the strongest in the three alloys. Microstructural examination showed many precipitates of a TCP phase in the creep specimen of alloy A, especially near the rupture portion, and this is the reason why alloy $A$ is weaker than alloy $B$. The creep rupture strength of alloy $C$ is also lower than that of alloy $B$ since alloy $C$ is not strengthened enough by solution hardening. Thus we selected alloy $\mathrm{B}$ as a final alloy. This alloy was designated as TMS-82+ and further examination was conducted.

\section{The Ileat-Treatment Capability of TMS-82+}

Figure 4 shows the microstructures of TMS- $82+$ in the as-cast condition and after heating for 2 hour between $1280^{\circ} \mathrm{C}$ and $1360^{\circ} \mathrm{C}$. Most of the $\gamma^{\prime}$ precipitates are dissolved into the $\gamma$ phase at $1280^{\circ} \mathrm{C}$. At $1360^{\circ} \mathrm{C}$, incipient melting occurs. These show that TMS- $82+$ has a heat treatment window over $60^{\circ} \mathrm{C}$ wide providing a very good heat treatment processability.

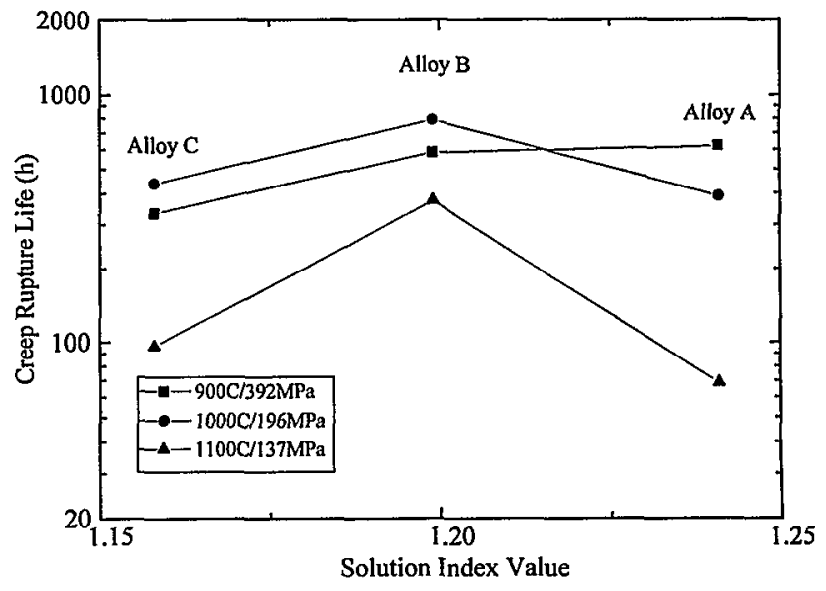

Figure 3: Creep rupture lives of alloy A,B and C plotted against the Solution Index value. 


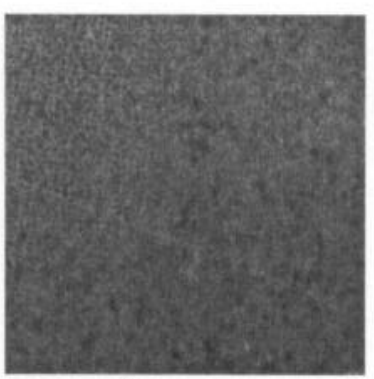

As-cast

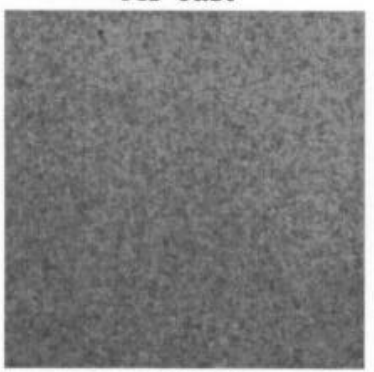

$1300^{\circ} \mathrm{C}$

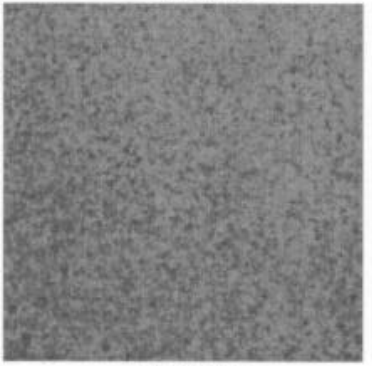

$1340^{\circ} \mathrm{C}$ $1280^{\circ} \mathrm{C}$

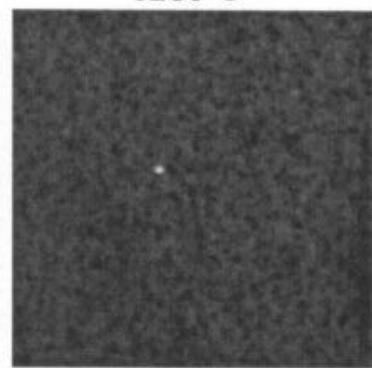

$1320^{\circ} \mathrm{C}$

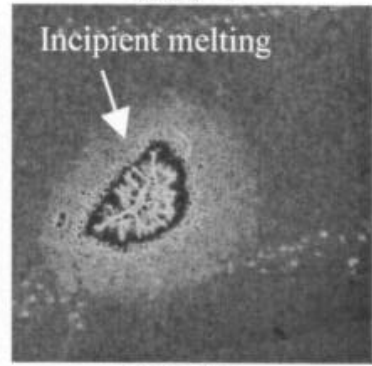

$1360^{\circ} \mathrm{C}$

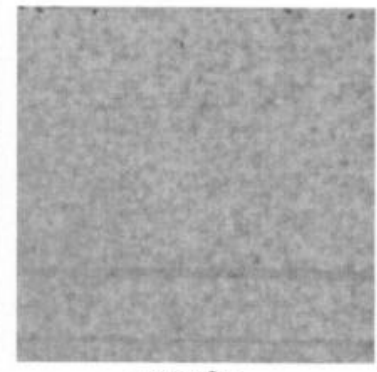

$\stackrel{\longmapsto}{10 \mu \mathrm{m}}$

Figure 4: The result of solution treatment trials at different temperature for 2 hours with TMS-82+.

\section{Creep Property}

Figure 5 shows the creep rupture curves of TMS-82+, CMSX-4 ${ }^{[4]}$, TMS- $75^{[7]}$, Rene'N5 ${ }^{[5]}$, Rene'N6 ${ }^{[5]}$ and a patent alloy (alloy 11) containing $\mathrm{Ru}^{[12]}$. The creep rupture strength of TMS-82+ is superior to those of the second generation SC superalloys such as CMSX-4 and Rene'N5 in all the stress and temperature range, the temperature capability at $137 \mathrm{MPa} / 10^{5}$ hours of TMS- $82+$ is $50-60^{\circ} \mathrm{C}$ higher than Rene'N5. Moreover, in the higher temperature and lower stress range, TMS- $82+$ is stronger than the third generation SC superalloys such as TMS-75 and Rene'N6, and even the Ru containing US patented alloys ${ }^{[12]}$.
Figure 6 shows creep curves of TMS-82+ and the third generation SC superalloy TMS-75. Cross section micrographs of creep interrupted specimens cut along the longitudinal direction in the middle of a specimen are shown in Figure 7. A so-called raft structure is observed both in TMS-82+ and TMS-75; $\gamma^{\prime}$ precipitates are connected with each other normal to the stress axis. Third generation SC superalloys tend to precipitate the TCP phase which is known to reduce the creep rupture strength ${ }^{[9][10]}$. However, there is no precipitates of TCP phase, the creep strain rate of TMS-75 is, nevertheless, larger than that of TMS-82+. This suggests that the large creep strain rate of TMS-75 compared with TMS-82+ in this condition is not attributed to precipitation of TCP phase.

As for the morphology of the raft structure, more continuous $\gamma^{\prime}$ platelets are observed in TMS-82+ compared with TMS-75. This structure improves the creep resistance effectively by providing effective barriers to dislocation climb around $\gamma^{\prime}$ platelets $^{[13]}$.

Table. III shows the lattice misfit of TMS-82+ and TMS-75 measured at $1100^{\circ} \mathrm{C}$ by $\mathrm{X}$-ray diffraction techniques ${ }^{[14]}$.The lattice misfit of TMS- $82+$ is negative and the absolute value is larger than that of TMS-75. The large negative misfit enhances the $\gamma^{\prime}$ rafting ${ }^{[15]}$ which improves creep strength of TMS- $82+$.

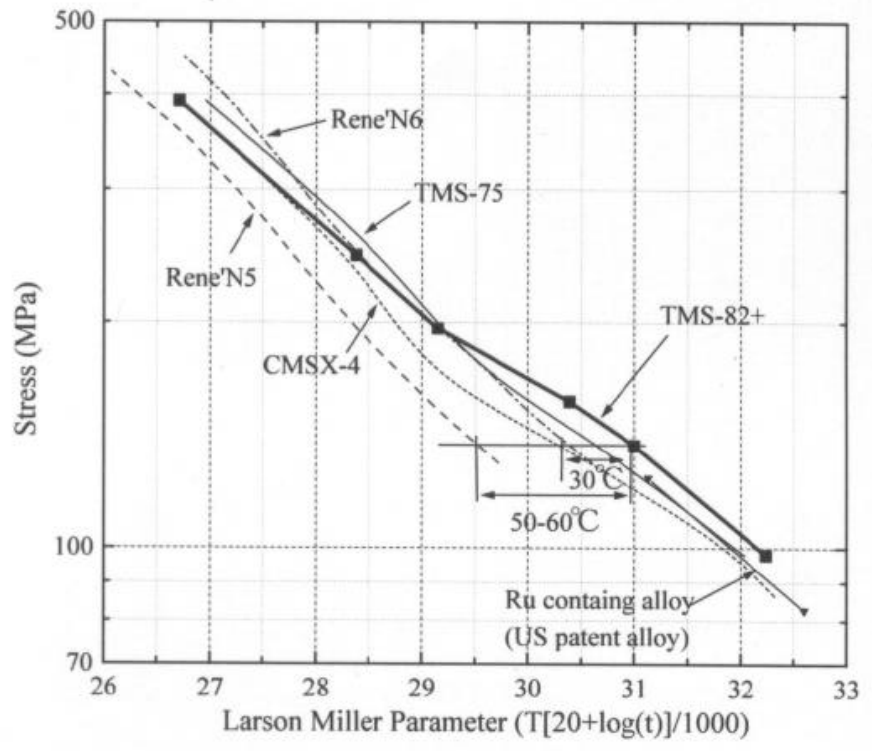

Figure 5 : Creep rupture strengths of TMS-82+, Rene'N5, CMSX-4, Rene'N6, TMS-75 and alloyl1 (Ru containing alloy). 

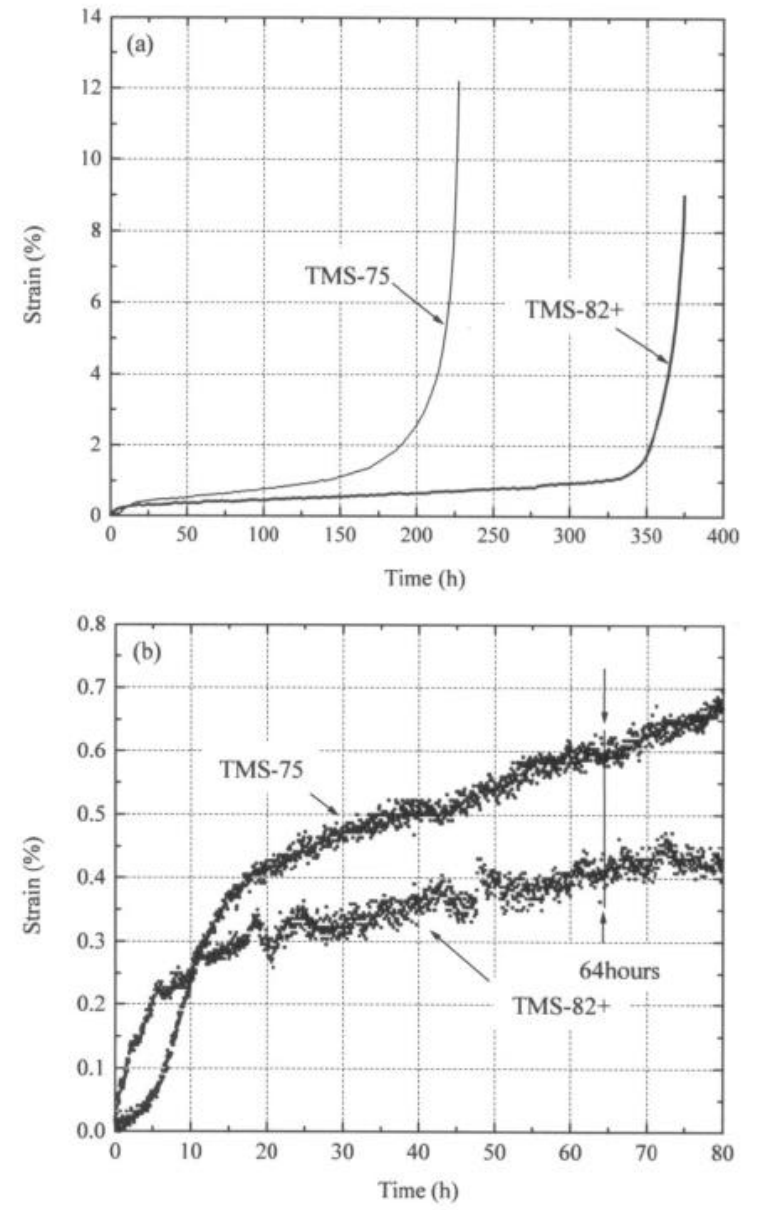

Figure 6: Creep curves of TMS- $82+$ and TMS- 75 at $1100^{\circ} \mathrm{C}$ /137MPa condition.

Table III Lattice misfit, creep strain and creep strain rate of TMS-82+ and TMS-75 at 64 hours creep under $1100^{\circ} \mathrm{C} / 137 \mathrm{MPa}$.

\begin{tabular}{|c|c|c|c|}
\hline & $\begin{array}{c}\text { Lattice misfit } \\
\left(1100^{\circ} \mathrm{C}\right)\end{array}$ & Creep strain & $\begin{array}{c}\text { Creep strain } \\
\text { rate }\end{array}$ \\
\hline TMS-82+ & -0.24 & $0.41 \%$ & $2.4 \times 10^{-3} \% / \mathrm{h}$ \\
\hline TMS-75 & -0.08 & $0.59 \%$ & $3.4 \times 10^{-3} \% / \mathrm{h}$ \\
\hline
\end{tabular}

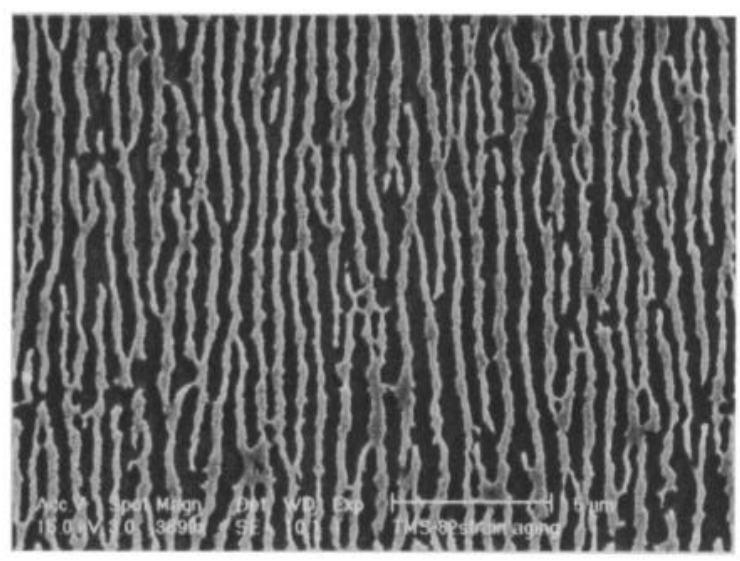

(a) TMS-82+

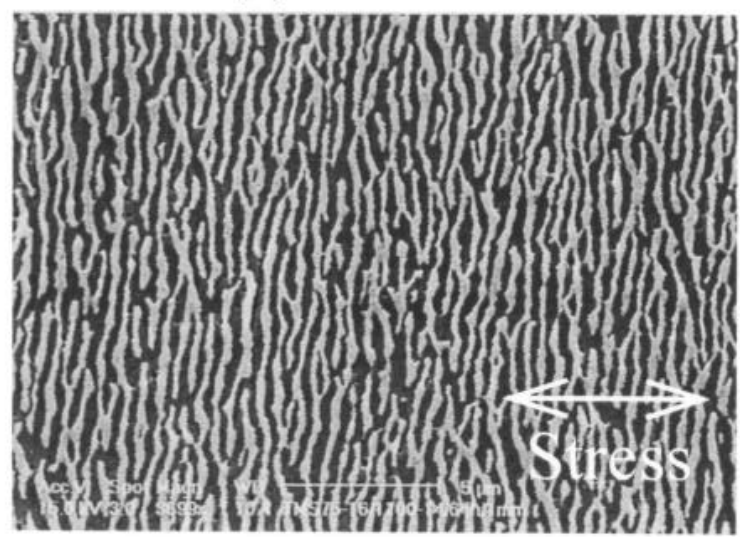

(b) TMS-75

Figure 7: Raft structures in (a)TMS-82+ and (b)TMS-75 ; creep interrupted at 64 hours under $1100^{\circ} \mathrm{C} /$ 137MPa condition.

Figure 8 shows TEM images of interfacial dislocation networks between $\gamma$ and $\gamma^{\prime}$ phases in the creep interrupted specimen of TMS-82+ and TMS-75 after 64 hours at $1100^{\circ} \mathrm{C} / 137 \mathrm{MPa}$. The interfacial dislocation network is formed due to the misfit strain between $\gamma$ and $\gamma^{\prime}$ phases and additionally due to the applied stress leading to creep. The size of the dislocation network in TMS-82+ is finer than TMS-75 as shown in Figure 8. It is considered that the finer dislocation network in TMS-82+ is formed mainly by the larger negative lattice misfit which improves the creep strength by preventing dislocation movement especially the cutting motion into $\gamma^{\prime}$ precipitate. 


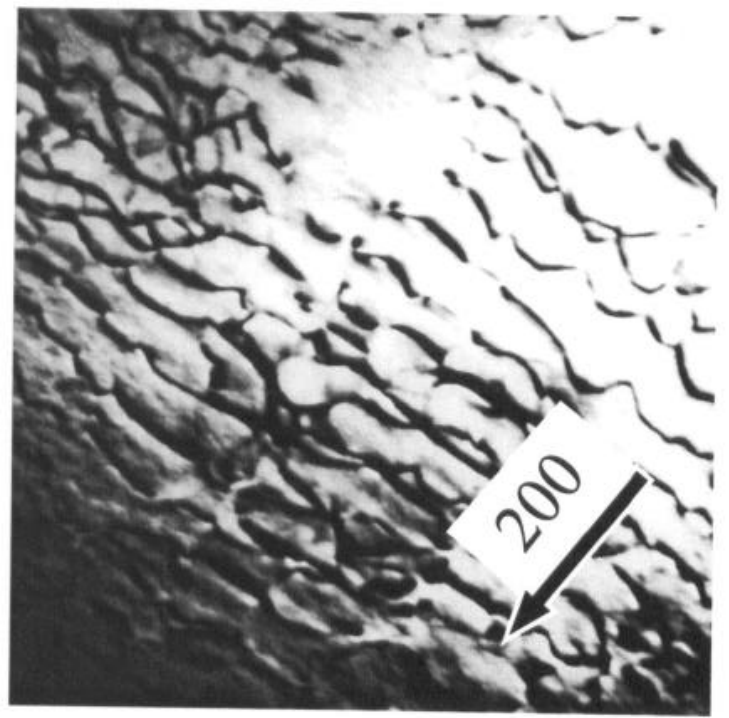

(a) TMS-82+

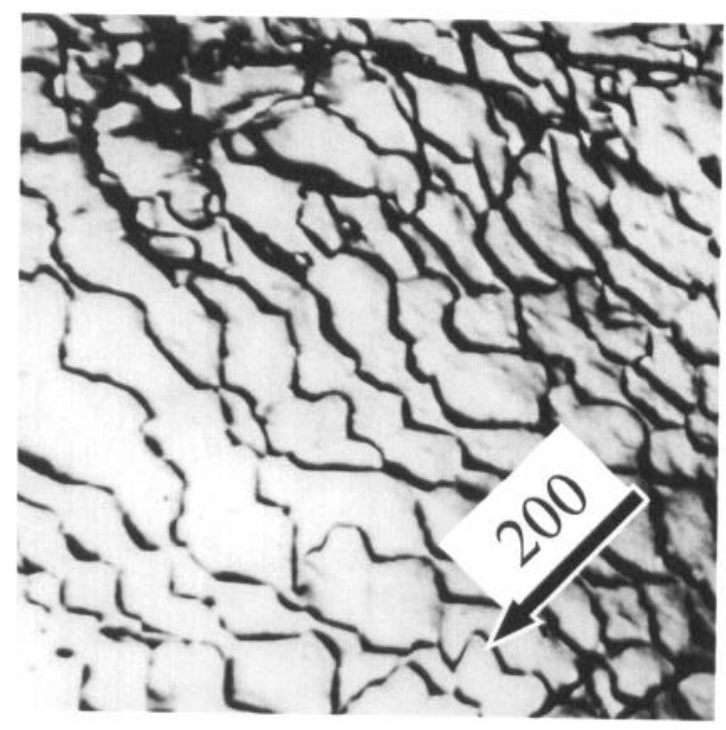

(b) TMS-75

This is another reason that TMS-82+ has high creep rupture strength compared with other second and third generation SC superalloys. Figure 9 shows creep strain rates plotted against dislocation network spacings along $g=[200]$ direction. This indicates that creep strain rate decreases as the network spacing becomes fine. Once the good rafted structure is established as shown in TMS-82+, dislocation climb becomes very difficult. In this condition dislocation cutting into $\gamma^{\prime}$ platelet is forced to be the predominant creep mechanism and then the finer dislocation network can act as a very effective barrier to this.

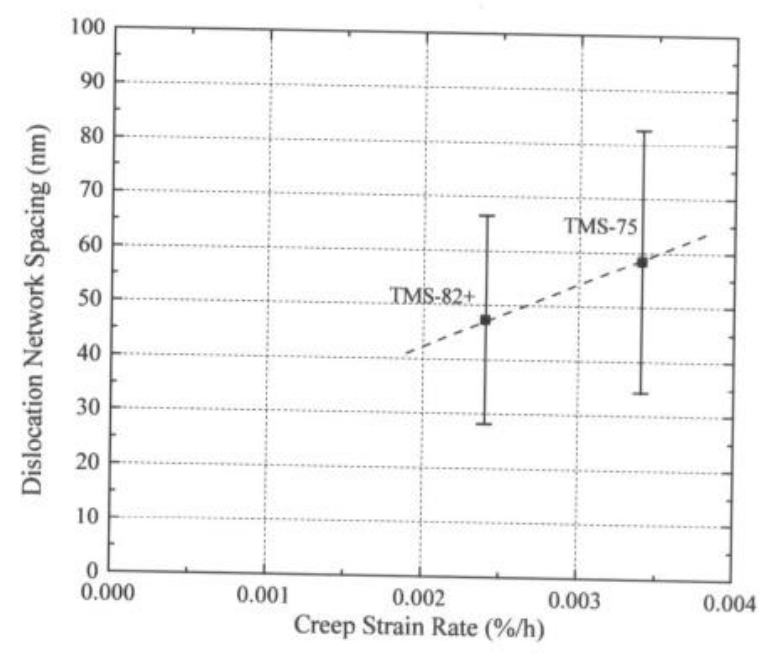

Figure 9: Dislocation network spacing of dislocation networks of TMS-82+ and TMS-75 at $1100^{\circ} \mathrm{C} / 137 \mathrm{MPa}$ for 64 hours plotted against their creep strain rate.

\section{Phase Stability of TMS-82+}

Figure 10 shows the end section of TMS-82+ creep rupture specimen tested at $1000^{\circ} \mathrm{C} / 196 \mathrm{MPa}$ for 790 hours. A very small amount of TCP precipitates are observed. In other conditions such as $1100^{\circ} \mathrm{C} / 137 \mathrm{MPa}$ and $1100^{\circ} \mathrm{C} / 98 \mathrm{MPa}$, TCP particles were also precipitated, but the amounts are small. This reveals that TMS- $82+$ has a good phase stability. 


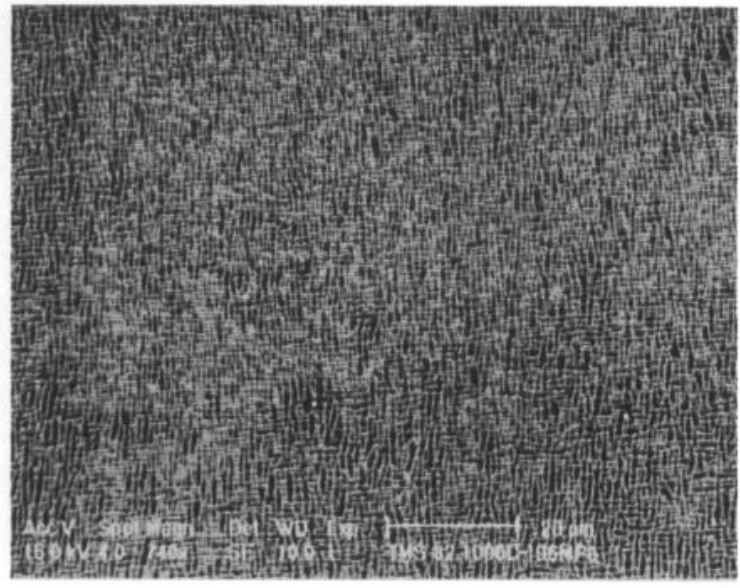

$\longmapsto$

Figure 10: Microstructure of TMS-82+ after 790h aged at $1000^{\circ} \mathrm{C}$.

We developed a new SC superalloy which has excellent creep rupture properties compared with present second and third generation SC superalloys. Now, other properties, such as a longer term phase stability, hot corrosion resistance, high and low cycle fatigue properties are being examined. A castability test using a dummy mold of gas turbine blade is being conducted. After the laboratory tests, a turbine rotating test in an actual gas turbine is scheduled in mid 2000 year.

\section{Conclusion}

In this study, it was intended to develop a new SC superalloy which has excellent creep properties compared with present second generation SC superalloys. The following results were obtained.

1. We developed a new SC superalloy with NRIM-ADP and optimized the chemical composition through experimental evaluation. The creep strength of the developed alloy, TMS-82+, is higher than that of third generation SC superalloys at high temperature and low stress condition.

2.In microstructual observation, the length of raft structure perpendicular to the stress axis of TMS-82+ is longer than that of third generation SC superalloy, TMS-75. The dislocation network in TMS-82+ is finer than that of TMS-75. These are considered to be the reasons for the creep properties of TMS-82+ being superior to that of other SC superalloys especially in high temperature and low stress condition.
3.TMS- $82+$ has a large negative lattice misfit between $\gamma$ and $\gamma^{\prime}$ phases which accelerated the formation of raft structure and very fine dislocation network, attributing the high creep strength.

\section{Acknowledgements}

We would like to express sincere thanks to Dr.M.Maldini, Mr.T.Yokokawa, Dr.H.Murakami, Dr.Y.Yamabe-Mitarai, Mr. S.Nakazawa, Dr.M.Osawa and Mr.M.Sato of National Research Institute for Metals for their advice. We would like to express sincere thanks to Dr.P.E.Waudby of Ross \& Catherall ltd. for making the master ingot and analyzing the compositions of developed alloys.

\section{References}

1.T.Aizawa,"The out line of Yokohama ACC and Future Plan of ACC Power Generation ,"Proc.of 1995 Yokohama int. gas turbine congress, (Tokyo : Gas Turbine Society of Japan, 1995), No3: 341- 348.

2.H.Yokoyama,"Advanced Technology of ABB Gas Turbine", $28^{\text {th }}$ gas turbine seminar text, (Tokyo: Gas Turbine Society of Japan, 2000), 77-86.

3.I.Myougan,"Single Axis Combined Cycle Plant of Siemens", $28^{\text {th }}$ gas turbine seminar text, (Tokyo: Gas Turbine Society of Japan, 2000), 101-110.

4.A.D.Cetel and D.N.Duhl, "Second-generation Nickel-base Single Crystal Superalloy",Superalloys 1988,ed.D.N.Duhl, et.al. (Warrendale, PA : The Minerals, Metals \& Materials, Society, 1988), 235-244.

5. G.L.Erickson and K.Harris, "DS and SX Superalloys for Industrial Gas turbines", Material for Advanced Power Engineering 1994, ed. D.Coutsouradis et.al. (Kluwer Academic Publishers, 1994), Part I :1055- 1074.

6.W.S.Walston et.al.,"ReneN6 : Third Generation Single Crystal Superalloys", Superalloys1996, ed. R.D.Kissinger et.al. (Warrendale, PA : The Minerals, Metals \& Materials, Society, 1996), 27-34.

7.G.L.Erickson, "The Development and Application of CMSX-10", Superalloys1996, ed. R.D.Kissinger et.al. (Warrendale, PA : The Minerals, Metals \& Materials, Society, 1996), 35-44. 
8.Y.Koizumi et.al., "Third Generation Single Crystal Superalloys with Excellent Processability and Phase Stability", Material for Advanced Power Engineering, ed. J.Lecomte-Beckers et.al (Kluwer Academic Publishers, 1998), Part II, 1089-1098.

9. R.Darolia et.al., "Formation of Topologically Closed Packed Phases in Nickel Base Single Crystal Superalloys" Superalloys1988, ed.D.N.Duhl et.al. (Warrendale, PA : The Minerals, Metals \& Materials, Society 1988), 255-264.

10.T.Hino et.al. , "Design of High Re Containing Single Crystal Superalloys for Industrial Gas Turbines", Material for Advanced Power Engineering, ed. J.Lecomte-Beckers et.al (Kluwer Academic Publishers, 1998), Part.II: 1129- 1137.

11.H.Harada et.al., "Phase Calculation and Its Use in Alloy Design Program for Nickel-Base Superalloys", Superalloys 1988, ed.D.N.Duhl et.al. (Warrendale, PA : The Minerals, Metals \& Materials, Society 1988),733-742.

12.K.S.O'hara et.al., U.S.Patent 5,482,789 "Nickel Base Superalloy and Article".

13.MacKay,R.A. et.al., "Factors which Influence Directional Coarsening of $\gamma^{\prime}$ during Creep in Nickel-base Superalloy Single Crystals", Superalloys1984, ed. M.Gell,et.al., (Warrendale, PA : The Minerals, Metals \& Materials, Society, 1984), 135-144.

14.T.Yokokawa and M.Osawa, private communication with author, National Research Institute for Metals, 25 Februrary 2000.

15.D.D.Pearson et.al., "Stress Coarsening of $\gamma^{\prime}$ and Its Influence on Creep Properties of a Single Crystal Superalloy ", Superalloys 1980 , ed.J.K.Tien et.al. (Warrendale, PA : The Minerals, Metals \& Materials, Society, 1980), 513-520. 